\title{
Oral microbiota carriage in patients with multibracket appliance in relation to the quality of oral hygiene
}

\author{
Katharina Klaus $^{1 *}$ (D), Johanna Eichenauer ${ }^{2}$, Rhea Sprenger ${ }^{3}$ and Sabine Ruf ${ }^{1}$
}

\begin{abstract}
Background: The present study aimed to investigate the prevalence of oral microbiota (Candida species (spp.), Streptococcus mutans, and Lactobacilli) in patients with multibracket (MB) appliances in relation to the quality of oral hygiene.

Saliva and plaque samples were collected from three groups of 25 patients each (good oral hygiene (GOH), poor oral hygiene (POH), and poor oral hygiene with white spot lesions (POH/WSL)). Counts of colony forming units (CFU) of the investigated oral microbiota were compared using Chi-square and Mann-Whitney $U$ tests.

Results: Both saliva and plaque samples showed a high prevalence of Candida spp. in all patients (saliva: $73.4 \%$, plaque: $60.9 \%$ ). The main Candida species was C. albicans. The salivary CFU of Candida spp. in the GOH group was significantly lower than that in the POH group $(p=0.045)$ and POH/WSL group $(p=0.011)$. S. mutans was found in the saliva and plaque samples of all patients. Lactobacilli were found in the saliva samples of all patients and in $90.7 \%$ of the plaque samples. In the saliva samples, the CFU of Lactobacilli were more numerous in the POH and POH/WSL groups than in the $\mathrm{GOH}$ group $(p=0.047)$.
\end{abstract}

Conclusions: The investigated sample of patients showed a high carriage of oral Candida spp. Patients with WSL formation during MB appliance treatment exhibited higher counts of Candida and Lactobacilli compared with patients with good oral hygiene. Independent of oral hygiene quality, S. mutans was detected in all patients.

Keywords: Candida, Streptococcus mutans, Lactobacilli, Oral hygiene, Fixed appliance, White spot lesions

\section{Background}

The insertion of a multibracket (MB) appliance induces a change in the number and composition of oral microflora. Besides the increase in potential cariogenic bacteria such as Streptococcus mutans, Lactobacilli, and periodontal pathogenic microorganisms, a marked increase in oral yeasts also occurs [1-6]. In particular, colonization with Candida albicans is of interest for orthodontists because of the fungus' possible cariogenic effect [7-10], which has been demonstrated in vitro [11-13] and in vivo [14-20].

During orthodontic treatment with $\mathrm{MB}$ appliances, the development of white spot lesions (WSL) is an undesirable side effect with an incidence rate of $30 \%-70 \%[6,21,22]$. WSL can develop as quickly as within 4 weeks [23]. Although patients with poor oral hygiene $(\mathrm{POH})$ during treatment are reportedly affected $[6,24,25]$, WSL are quite unpredictable from a clinical perspective. Some patients develop WSL despite acceptable oral hygiene, while others with consistently $\mathrm{POH}$ remain unaffected.

Therefore, the present pilot study aimed to analyze and compare oral microbiota in patients with MB appliances, with special emphasis on Candida spp. colonization. The quality of oral hygiene and the development of WSL were considered in this study. The null hypothesis was no difference in the amount of Candida, S. mutans, and Lactobacilli colonization among patients with good oral hygiene $(\mathrm{GOH}), \mathrm{POH}$, or $\mathrm{POH}$ with WSL.

\footnotetext{
*Correspondence: Katharina.Klaus@dentist.med.uni-giessen.de

1 Department of Orthodontics, Justus-Liebig University Giessen,

Schlangenzahl 14, 35392 Giessen, Germany

Full list of author information is available at the end of the article
} 


\section{Methods}

Ethical approval was granted by the ethical committee of the medical faculty of the Justus-Liebig-University of Giessen, Germany (No. 95/08).

Patients were selected from the Department of Orthodontics at Justus-Liebig-University Giessen, Germany. In general, after placement of a MB appliance, all patients of the department received the same standardized oral care instructions regarding frequency, technique, and duration of daily tooth brushing with fluoridated toothpaste, use of interdental brushes, and additional weekly fluoride gel application.

The inclusion criteria comprised patients aged 11 years or older without craniofacial anomalies, general diseases, or drug intake undergoing active MB appliance treatment in both jaws for at least three months. All selected patients were prospectively monitored for the quality of their oral hygiene at three consecutive regular appointments.

Dental plaque at selected index teeth $(13,21,24,33$, 41, and 44) was visually inspected, and oral hygiene was categorized as follows:

1. GOH: no visible dental plaque on index teeth and no signs of gingival inflammation.

2. Average oral hygiene $(\mathrm{AOH})$ : small amounts of dental plaque on index teeth and mild signs of gingival inflammation.

3. $\mathrm{POH}$ : massive dental plaque on index teeth especially between the bracket and gingival margin, as well as marked signs of gingival inflammation.

4. POH with new WSL (POH/WSL): massive dental plaque on index teeth especially between the bracket and gingival margin, as well as marked signs of gingival inflammation and development of WSL during MB treatment. Possible pre-orthodontic WSL were excluded by analyzing the pre-treatment intraoral images.

Patients with consistent scorings of $\mathrm{GOH}$ or $\mathrm{POH}$ with/ without WSL formation for three consecutive appointments were considered for possible inclusion in the present study. Patients with $\mathrm{AOH}$ were excluded. Written informed consent was obtained from the patients and their parents. For each group $(\mathrm{GOH}, \mathrm{POH}$, and $\mathrm{POH} /$ WSL), the first 25 patients fulfilling the abovementioned criteria were included.

The study appointment occurred during the next regular control appointment. Patients were instructed to stop oral hygiene for $24 \mathrm{~h}$ before the appointment (tooth brushing/ antibacterial oral rinsing) to ensure a sufficient amount of plaque for sampling even in patients with $\mathrm{GOH}$.

The dental status was checked using a slight modification of the DMF-T-index [26]. The index was modified to assess orthodontic patients. Tooth agenesis, extractions caused by orthodontic treatment plan, and impacted teeth were not scored as missing teeth.

The plaque samples were obtained by sterilized swabs (Nerbe plus, Winsen/Luhe, Germany) from the enamel surfaces along the gingival margin of the index teeth. In all patients of the POH/WSL group, a second plaque sample was obtained from the affected WSL surface regions with a probe tip and then applied on a second swab.

Saliva secretion was stimulated by chewing a paraffin wax pellet over a period of $5 \mathrm{~min}$. The entire amount of saliva produced during that period was collected in a single-use plastic cup. From this sample, $2 \mathrm{ml}$ of saliva was extracted using a sterile syringe (B. Braun, Melsungen, Germany) and used for further analysis.

Candida counts were identified with Sabouraud agar (Merck, Darmstadt, Germany) for the saliva samples. Depending on the number of colony forming units (CFU) per milliliter of saliva, counts were categorized into 0 (none), 1 (isolated, $<10 \mathrm{CFU} / \mathrm{ml}), 2$ (moderate, 10-10 ${ }^{2} \mathrm{CFU} / \mathrm{ml}$ ), 3 (many, $10^{2}-10^{3} \mathrm{CFU} / \mathrm{ml}$ ), and 4 (massive, $>10^{3} \mathrm{CFU} / \mathrm{ml}$ ). Candida species were differentiated by an Auxacolor ${ }^{\mathrm{TM}}$ 2-Test (Bio-Rad, Marnes-laCoquette, France). Furthermore, the amounts of $S$. mutans and Lactobacilli were counted using the CRT ${ }^{\oplus}$ bacteria test (Ivoclar Vivadent, Schaan, Liechtenstein). The number of CFU per milliliter of saliva was categorized as 0 (none), 1 (moderate, $<10^{5} \mathrm{CFU} / \mathrm{ml}$ ), and 2 (many, $\geq 10^{5} \mathrm{CFU} / \mathrm{ml}$ ). For plaque samples, the test manufacturers recommended classifying the occurrence of $S$. mutans, Lactobacilli, and Candida in terms of a binary (yes/no) decision only, because the plaque samples have no defined volume.

Statistical analysis was performed by IBM SPSS Statistics 22 (IBM Company, Chicago, IL, USA). Descriptive data analysis was conducted by exploring means, standard deviations, minima, and maxima. The data were not normally distributed, and the differences between groups were assessed using the Chi-square and Mann-Whitney U tests.

\section{Results}

The general descriptive characteristics of the final patient sample are given in Table 1 . The mean age of the total sample was $14.4 \pm 1.5$ years and did not differ significantly among the three oral hygiene groups. The gender distribution was nearly equal in the total sample and in the POH/WSL group. Female predominance was found in the $\mathrm{GOH}$ group, whereas male predominance was noted in the $\mathrm{POH}$ group. The DMF-T-index was generally very low (mean range: $0-0.1$ ) and did not differ among the oral hygiene groups.

At the time of saliva and plaque sample collection, the mean wearing time of the $\mathrm{MB}$ appliance in the $\mathrm{GOH}$ group (14.9 \pm 7.9 months) was insignificantly higher than 
Table 1 Demographic characteristics of the studied patient sample $(n=75)$ and their fixed appliance treatment duration at the time of the study

\begin{tabular}{lllll}
\hline Group & Age (years) mean \pm SD & Male & Female & MB in situ (months) mean \pm SD \\
\hline Total sample & $14.4 \pm 1.8$ & 36 & 39 & $16 \pm 9.2$ \\
$\mathrm{GOH}$ & $14.6 \pm 1.8$ & 6 & 19 & $14.9 \pm 7.9$ \\
$\mathrm{POH}$ & $14.0 \pm 1.4$ & 16 & 9 & $13.4 \pm 6.7$ \\
$\mathrm{POH} /$ WSL & $14.6 \pm 1.3$ & 14 & 11 & $19.6 \pm 11.3$ \\
\hline
\end{tabular}

$S D$ standard deviation, $M B$ multibracket appliance, $G O H$ good oral hygiene, $P O H$ poor oral hygiene, $P O H / W S L$ poor oral hygiene with white spot lesions

that in the POH group $(13.4 \pm 6.7$ months $)$. The POH/ WSL group showed the longest wearing period (19.6 \pm 11.3 months) with a significant difference from the other groups $(p=0.017)$.

Analysis of the saliva samples revealed that $73.4 \%$ of the patient sample were Candida carriers. About half of the carrier samples $(49.4 \%, n=37)$ showed isolated to moderate numbers of CFU, whereas $24 \%(n=18)$ presented many to massive CFU. CFU of Candida spp. were significantly lower in the GOH group than in the $\mathrm{POH}$ group $(p=0.045)$ and POH/WSL group $(p=0.011)$ (Fig. 1). Saliva samples of Candida carriers $(n=54)$ showed C. albicans in $83.3 \%(n=45)$, C. dubliniensis in $14.8 \%$ $(n=8)$, and C. albicans II in $1.9 \%(n=1)$. No significant difference in the distribution of species was found among the different oral hygiene groups.

S. mutans and Lactobacilli were detected in the saliva samples of all patients. Patients with $\mathrm{POH}$ irrespective of WSL formation presented higher counts of $S$. mutans, but the difference was not statistically significant (Fig. 2). High Lactobacilli CFU were noted in $52 \%$ of patients in the $\mathrm{GOH}$ group. A comparable amount of CFU was found in $60 \%$ and $84 \%$ of patients in the $\mathrm{POH}$ group and $\mathrm{POH} / \mathrm{WSL}$ group, respectively. This difference was statistically significant $(p=0.047$; Fig. 3$)$. For the saliva samples, the null hypothesis regarding $S$. mutans was accepted but rejected in Candida and Lactobacilli.

Analysis of the plaque samples revealed a $60.9 \%$ prevalence of Candida carriers in the total sample. In the $\mathrm{POH} / \mathrm{WSL}$ patients, the plaque samples from the index teeth showed an insignificantly higher Candida prevalence $(62.4 \%)$. The second plaque samples from the affected white spot enamel regions exhibited only a slightly and insignificantly different prevalence of $64 \%$.

Among the Candida carriers $(n=46), 82.6 \%(n=38)$ of the carriers showed C. albicans, $15.2 \%(n=7)$ presented C. dubliniensis, and C. albicans II was found in $2.2 \%$ ( $n=$ 1). As in the saliva samples, the distribution of Candida species revealed no statistically significant difference among the oral hygiene groups. Similar to the saliva samples, $S$. mutans was verified in the plaque samples of all patients, whereas Lactobacilli were found in $90.7 \%$ ( $n=$ 68 ) of all plaque samples. For the plaque samples, the null hypothesis regarding all types of microbiota was accepted.

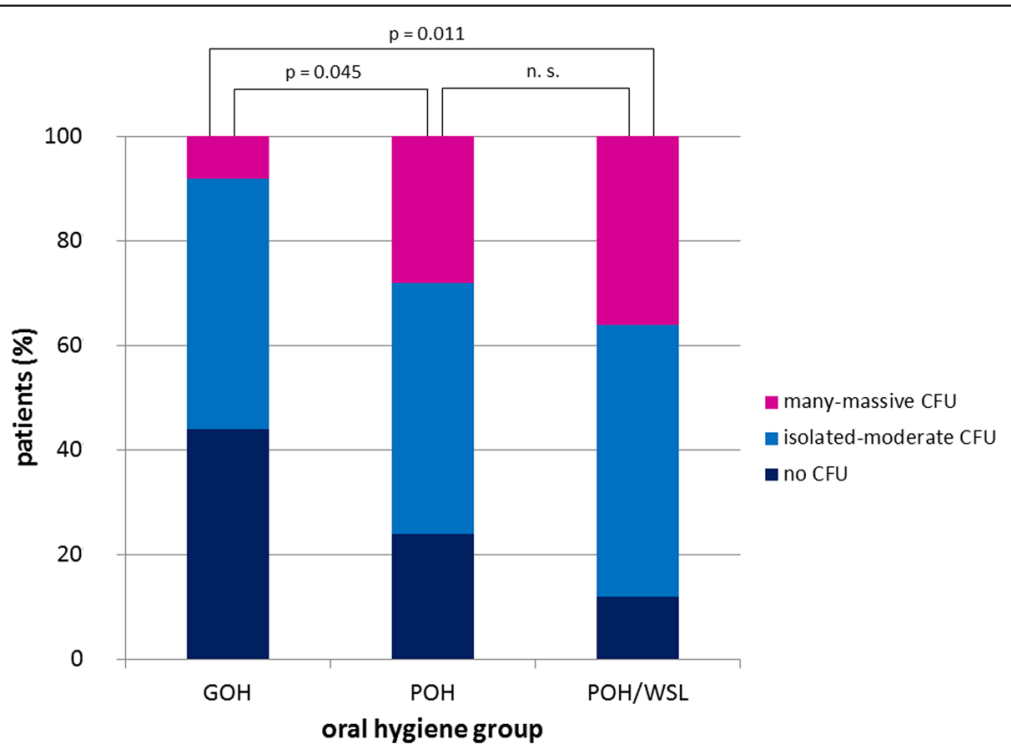

Fig. 1 Relative Candida carriage in patients' saliva in relation to the oral hygiene groups. A significant difference was found between the GOH and $\mathrm{POH}$ groups $(p=0.045)$, as well as between the $\mathrm{GOH}$ and POH/WSL groups $(p=0.011)$ 


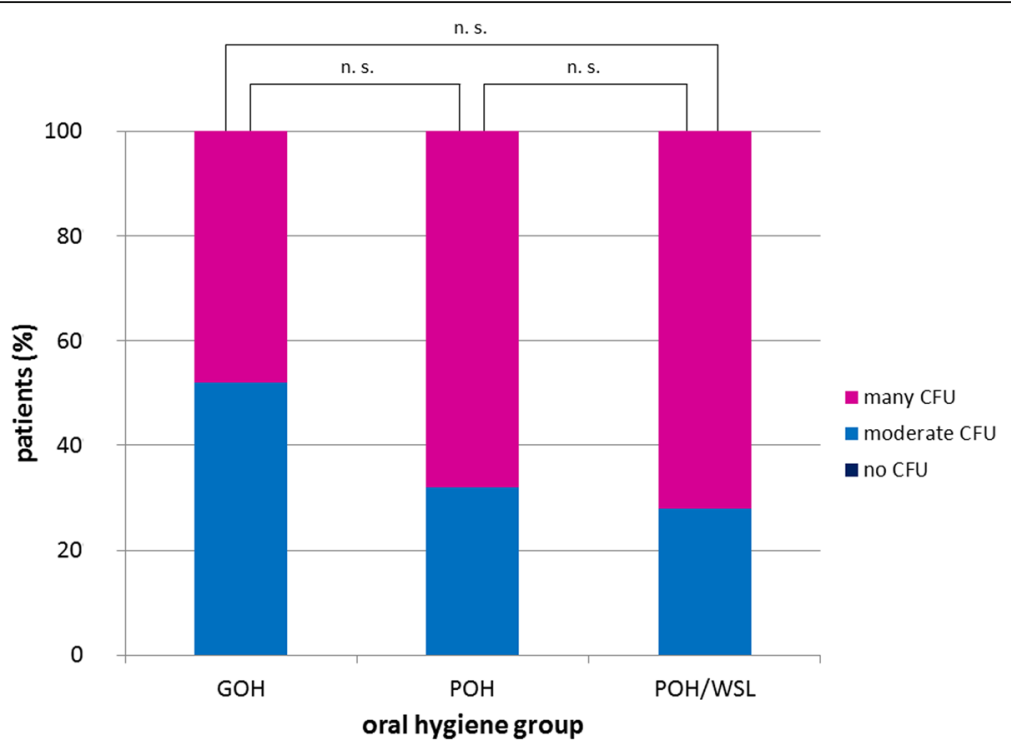

Fig. 2 Relative S. mutans carriage in patients' saliva in relation to the oral hygiene groups. No significant difference was found among the groups

\section{Discussion}

Counts of oral microbiota peak at about three months after insertion of a fixed appliance [3, 27-30]. Although most studies [3, 28-30] reported a slight decrease thereafter, Arslan et al. [27] found a consistent increase in Candida, S. mutans, and Lactobacilli counts up to 12 months of treatment. Despite the slight decrease reported by the other studies, patients showed consistently higher counts of oral microbiota compared with pretreatment [28-30]. In the present patient sample, the mean treatment duration at the study appointment ranged between 13.4 and 19.6 months with a significantly longer treatment time in the POH/WSL group, which was far longer than that in all other studies in the literature. For the POH/WSL group in the present study, the influence of oral microbiota or longer treatment duration on the development of WSL could not be clarified. However, given the cross-sectional design of the present study, the development of microbial counts in all the investigated groups during the treatment period remains unclear.

In the current literature, oral Candida carrier rates vary between $28.6 \%$ and $57.2 \%$, depending on the age of the examined individuals and the microbiological sampling method [31-36]. During orthodontic treatment, an even greater variation with prevalence rates between $8.3 \%$ and $78.8 \%$ was reported $[1,3,27,37]$. The results of the present study corresponded to the top end of these data with Candida prevalence in dental plaque of $60.9 \%$ and in saliva of $73.4 \%$ of the patients.

Unfortunately, no standard currently exists for oral microbiological sampling. According to the literature, the most popular sampling methods are stimulated and unstimulated saliva samples, centrifuged saliva samples, swabs from oral mucosa, plaque samples, and imprint cultures from different sites in the oral cavity [20]. When comparing results achieved by different sampling methods and different culture media [38], centrifuged saliva samples and imprint cultures showed a significantly higher sensitivity in detecting oral yeasts [39] than cultures from the other sampling methods. In the current literature, studies with patient samples comparable with the present investigation $[1,3,27,37]$ used various sampling methods (Table 2). Hägg et al. [3] used three different sampling methods, and the method closest to the sampling collection in our study (pooled plaque) revealed a clearly lower Candida rate (22.2 \%), in contrast to our study. Furthermore, $18.5 \%$ of their patients became Candida carriers during treatment. In the present work, the incidence rates of Candida infection could not be revealed because of the cross-sectional design of the study.

In concordance with the present findings, the current literature on oral yeast carriage indicated C. albicans as the dominant species both in orthodontic-treated patients $[3,27,37]$ and untreated individuals $[31,33]$. In our sample, $C$. dubliniensis was the second most frequent species and one patient presented $C$. albicans II; the literature reported other additional Candida strains. Given that $C$. albicans and C. dubliniensis present pronounced morphological similarities and some common tests are unable to differentiate them reliably [16], C. dubliniensis was possibly undetected in other investigations.

In general, the current literature agreed that $S$. mutans and Lactobacilli are characteristic for deep carious lesions $[14,15,40-42]$ and therefore not for initial carious lesions such as WSL. Aas et al. [40] verified high concentrations 


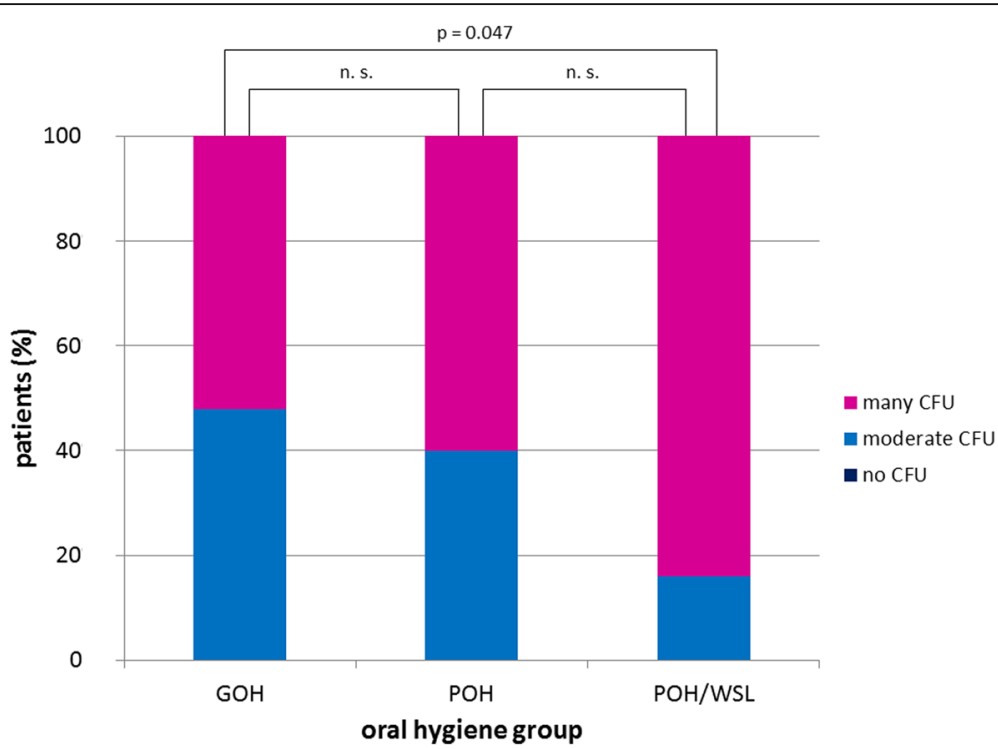

Fig. 3 Relative Lactobacilli carriage in patients' saliva in relation to the oral hygiene groups. A significant difference was observed between the $\mathrm{GOH}$ and $\mathrm{POH} / \mathrm{WSL}$ groups $(p=0.047)$

of Actinomyces and non-S. mutans-Streptococci in initial lesions, but they additionally emphasized that bacterial profiles in initial lesions are more complex than in advanced destruction stages. Badet and Thebaud [41] revealed a strong correlation between the DMF-T-index and amount of Lactobacilli counts and furthermore showed that Lactobacilli are not isolated from initial carious lesions because of weak adherence potential; retentive niches for adherence are required by Lactobacilli. A fixed orthodontic appliance inevitably presents retentive niches, so whether the high Lactobacilli counts in the present study are associated with WSL development or simply caused by better possibilities for plaque accumulation remains unclear.

However, an in vivo study by Arneberg et al. [43] revealed higher bacterial counts for S. mutans and Lactobacilli at initial carious lesion surfaces compared with the unchanged control surfaces of neighboring teeth, suggesting the participation of these microorganisms even in initial enamel lesions.
The association of C. albicans with dental caries has been frequently investigated in patients with severe early childhood caries [17-19, 44-46]. Current in vitro and in vivo studies $[12,13]$ demonstrated a symbiosis between C. albicans and S. mutans in dental plaque, in which the two microbiota strains stick together because of extracellular polysaccharides. During the maturation of dental plaque, large microcolonies of $S$. mutans and C. albicans can be observed after $42 \mathrm{~h}$ [13]. Falsetta et al. [13] investigated the effect of $S$. mutans and C. albicans in rodents and showed that co-infected animals present significantly more severe carious lesions, whereas rodents infected with either $S$. mutans or $C$. albicans revealed initial carious lesions. In the present study, a statistically significant relationship between the quality of oral hygiene and Candida colonization could only be demonstrated for the saliva samples. Furthermore, the present patient sample showed high counts of $S$. mutans and Lactobacilli in $\mathrm{POH}$ or $\mathrm{POH} / \mathrm{WSL}$ patients (significant for Lactobacilli in saliva only). In other words, all three

Table 2 Oral microbiological sampling methods and investigated time points used in previous studies to analyze Candida carriage in orthodontic patients

\begin{tabular}{|c|c|c|c|c|c|c|c|}
\hline \multirow[t]{2}{*}{ Study group } & \multicolumn{2}{|c|}{ Time points of investigation } & \multicolumn{2}{|c|}{ Type of appliance } & \multirow[t]{2}{*}{ Saliva sampling } & \multirow[t]{2}{*}{ Plaque sampling } & \multirow[t]{2}{*}{ Oral mucosa sampling } \\
\hline & Before insertion & $\overline{\text { During treatment }}$ & Fixed & $\overline{\text { Removable }}$ & & & \\
\hline Current study & - & $x$ & $\mathbf{x}$ & - & stimulated saliva & pooled plaque & - \\
\hline Addy et al. 1982 [1] & - & $\mathbf{x}$ & $\mathbf{x}$ & $x$ & - & - & imprint culture \\
\hline Hägg et al. 2004 [3] & $x$ & $\mathbf{x}$ & $\mathbf{x}$ & - & oral rinse & pooled plaque & imprint culture \\
\hline Arslan et al. 2008 [27] & $x$ & $\mathbf{x}$ & $\mathbf{x}$ & - & stimulated saliva & pooled plaque & - \\
\hline Arendorf, Addy 1985 [37] & $x$ & $\mathbf{x}$ & - & $x$ & - & - & imprint culture \\
\hline
\end{tabular}


microorganisms investigated in the present study influenced caries development, but the relative amount of their contribution and possible timing of their contribution remain unknown.

The first possible limiting factor of the present study is the lack of precise knowledge on the age and maturity of the dental plaque analyzed, because one cannot be sure that all patients followed the instructions to stop their oral hygiene for $24 \mathrm{~h}$ before the study appointment. Even if the patients followed this instruction, we are uncertain of the events that occurred during the previous days. Additionally, patients received no standardized information regarding eating or drinking between the appointments and before sample collection. Perhaps the comparability could have been improved slightly if all patients had a professional cleaning of their teeth, followed by the sampling appointment after a determined time period.

Furthermore, we cannot exclude the Hawthorne effect, because the knowledge about study participation and the special reminders about the study appointment given by the study team can evoke patient's behavior modification [47]. Moreover, such knowledge and reminders possibly influenced oral hygiene and in turn the oral microbiota in the weeks before study sampling.

One could also question the categorization of the patients into the $\mathrm{GOH}$ and $\mathrm{POH}$ groups based on the subjective judgement of the treating orthodontists instead of an objective measurement. However, even with objective measurements, cut-off values for the groups have to be defined, which still provide ample space for large variations in the quality of oral hygiene. Nevertheless, a quantitative plaque assessment would have improved the comparability with the results of Hägg et al. [3] and Arslan et al. [27].

Given the present results, oral Candida counts and $S$. mutans or Lactobacilli counts showed no clear interrelation to the development of WSL. The current literature revealed that the abovementioned organisms participated in initial enamel caries formation. Further prospective longitudinal clinical trials concerning changes in oral microbiota during $\mathrm{MB}$ treatment are required to clarify the developmental process of WSL.

\section{Conclusions}

The investigated sample of patients showed a high carriage of oral Candida spp., S. mutans, and Lactobacilli. Patients with WSL formation during $\mathrm{MB}$ appliance treatment showed higher counts of Candida and Lactobacilli compared with patients with $\mathrm{GOH}$. Independent of oral hygiene quality, S. mutans was detected in all patients.

\section{Abbreviations}

AOH: Average oral hygiene; CFU: Colony forming units; GOH: Good oral hygiene; MB: Multibracket; POH: Poor oral hygiene; POH/WSL: Poor oral hygiene with white spot lesions; Spp: Species; WSL: White spot lesions

\section{Acknowledgements}

The authors are grateful to Mrs. Ingrid Heidmann (Department of Periodontology and Department of Paediatric Dentistry of Justus-Liebig-University Giessen, Germany) for handling the microbial samples.

\section{Funding}

The authors declare that no funding was granted to the study by any company or institution.

\section{Availability of data and materials}

The datasets supporting the conclusions of this article can be requested from the corresponding author via E-mail.

\section{Authors' contributions}

JE and RS participated in the design and coordination of the study and carried out the collection of samples. KK carried out the collection of samples, analysis and interpretation of data, and drafted the manuscript. SR participated in the design of the study and gave final approval of the version to be published.

\section{Competing interests}

The authors declare that they have no competing interests.

Consent for publication

Not applicable.

\section{Ethics approval and consent to participate}

Ethical approval was granted by the ethical committee of the medical faculty of the Justus-Liebig-University of Giessen, Germany (No. 95/08). All patients and their parents signed their agreement to participate in the study and publish the results anonymously via written informed consent.

\section{Author details}

${ }^{1}$ Department of Orthodontics, Justus-Liebig University Giessen, Schlangenzahl 14, 35392 Giessen, Germany. ${ }^{2}$ Private orthodontic practice, Rosengasse 2, 35305 Grünberg, Germany. ${ }^{3}$ Private orthodontic practice, Marktgasse 2, 72070 Tübingen, Germany.

Received: 23 May 2016 Accepted: 18 October 2016

Published online: 28 October 2016

\section{References}

1. Addy M, Shaw C, Hansford P, Hopkins M. The effect of orthodontic appliances on the distribution of Candida and plaque in adolescents. $\mathrm{Br} \mathrm{J}$ Orthod. 1982;9:158-63.

2. Freitas AO, Marquezan M, Nojima Mda C, Alviano DS, Maia LC. The influence of orthodontic fixed appliances on the oral microbiota: A systematic review. Dental Press J Orthod. 2014;19:46-55.

3. Hägg U. Kaveewatcharanont P; Samaranayake YH, Samaranayake LP: The effect of fixed orthodontic appliances on the oral carriage of Candida species and Enterobacteriaceae. Eur J Orthod. 2004;26:623-9.

4. Hibino K, Wong PW, Hägg U, Samarayanake LP. The effects of orthodontic appliances on Candida in the human mouth. Int J Paed Dent. 2009;19:301-8.

5. Ren Y, Jongsma MA, Mei L, Van der Mei HC, Busscher HJ. Orthodontic treatment with fixed appliances and biofilm formation-a potential public health threat? Clin Oral Investig. 2014;18:1711-8.

6. Topaloglu-Ak A, Ertugrul F, Eden E, Ates M, Bulut H. Effect of orthodontic appliances on oral microbiota -6 month follow-up. J Clin Pediatr Dent. 2011;35:433-6.

7. De Carvalho FG, Silva DS, Hebling J, Spolidorio LC, Spolidorio DM. Presence of mutans streptococci and Candida spp. in dental plaque/dentine of carious teeth and early childhood caries. Arch Oral Biol. 2006;51:1024-8.

8. Hossain H, Ansari F, Schulz-Weidner N, Wetzel WE, Chakraborty T, Domann E. Clonal identity of Candida albicans in the oral cavity and the gastrointestinal tract of pre-school children. Oral Microbiol Immunol. 2003;18:302-8.

9. Klinke T, Guggenheim B, Klimm W, Thurnheer T. Dental caries in rats associated with Candida albicans. Caries Res. 2011;45:100-6.

10. Tufekci E, Dixon JS, Gunsolley JC, Lindauer SJ. Prevalence of white spot lesions during orthodontic treatment with fixed appliances. Angle Orthod. 2011;81:206-10.

11. Wetzel WE, Böhmer C, Sziegoleit A. In vitro Karies durch Candida albicans. Acta Med Dent Helv. 1997;2:308-13. 
12. Barbieri DSAV, Vicente VA, Fraiz FC, Lavoranti OJ, Svidzinski TIE, Pinheiro RL Analysis of the in vitro adherence of Streptococcus mutans and Candida albicans. Braz J Microbiol. 2007;38:624-31.

13. Falsetta ML, Klein Ml, Colonne PM, Scott-Anne K, Gregoire K, Pai CH, Gonzalez-Begne M, Watson G, Krysan DJ, Bowen WH, Koo H. Symbiotic relationship between Streptococcus mutans and Candida albicans synergizes virulence of plaque biofilms in vivo. Infect Immun. 2014;82:1968-81.

14. Van Houte J. Role of micro-oganisms in caries etiology. J Dent Res. 1994;73:672-81.

15. Van Houte J, Lopman J, Kent R. The final pH of bacteria comprising the predominant flora on sound and carious human root and enamel surfaces. J Dent Res. 1996;75:1008-14.

16. Wandelt S. Hefen in der menschlichen Mundhöhle und ihre Bedeutung für die Ätiologie der Karies. Dtsch Zahnärztl Z. 1969;24:486-528.

17. Wetzel WE, Sziegoleit A, Weckler C. Karies-Candidose im Milchgebiss. Notabene Medici. 1984;10:845-9.

18. Wetzel WE, Szeigoleit A. Karies-Candidose in Milch-, Wechsel- und bleibenden Gebissen. Hautnah Dermatol. 1990;4:40-5

19. Wetzel WE, Hanisch S, Sziegoleit A. Keimbesiedlung in der Mundhöhle be Kleinkindern mit nursing-bottle-syndrom. Schweiz Monatsschr Zahnmed. 1993;103:1107-12

20. Williams DW, Lewis MAO. Isolation and identification of candida from the oral cavity. Oral Dis. 2000;6:3-11.

21. Enaia M, Bock NC, Ruf S. White-spot lesions during MB appliance treatment: a challenge for clinical excellence. Am J Orthod Dentofacial Orthop. 2011; 140:e17-24.

22. Richter AE, Arruda AO, Peters MC, Sohn W. Incidence of caries lesions among patients treated with comprehensive orthodontics. Am J Orthod Dentofacial Orthop. 2011;139:657-64.

23. Ögaard B, Rölla G, Arends J, Ten Cate JM. Orthodontic appliances and enamel demineralization. Part 2. Prevention and treatment of lesions. Am J Orthod Dentofacial Orthop. 1988:94:123-8.

24. Heymann GC, Grauer D. A contemporary review of white spot lesions in orthodontics. J Esthet Restor Dent. 2013;25:85-95.

25. Lucchese A, Gherlone E. Prevalence of white-spot lesions before and during orthodontic treatment with fixed appliances. Eur J Orthod. 2013:35:664-8.

26. Klein H, Palmer C. Studies on dental caries. Pub Hlth Rep. 1939;53:1353-64.

27. Arslan SG, Akpolat N, Kama JD, Özer T, Hamamci O. One-year follow-up of the effect of fixed orthodontic treatment on colonization by oral candida. J Oral Pathol Med. 2008:37:26-9.

28. Peros K, Mestrovic S, Anic-Milosevic S, Slaj M. Salivary microbial and nonmicrobial parameters in children with fixed orthodontic appliances. Angle Orthod. 2011;81:901-6.

29. Petti S, Barbato E, Simonetti D'Arca A. Effect of orthodontic therapy with fixed and removable appliances on oral microbiota: a six-month longitudinal study. New Microbiol. 1997;20:55-62.

30. Ristic M, Vlohovic Svabic M, Sasic M, Zelic O. Clinical and microbiological effects of fixed orthodontic appliances on periodontal tissues in adolescents. Orthod Craniofoacial Res. 2007:10:187-95.

31. Arendorf T, Walker D. The prevalence and intra-oral distribution of Candida albicans in man. Arch Oral Biol. 1980;25:1-10.

32. Darwazeh AMG, Hammad MM, Al-Jamaei AA. The relationship between oral hygiene and oral colonization with Candida species in healthy adult subjects. Int J Dent Hygiene. 2010;8:128-33.

33. Moalic E, Gestalin A, Quinio D, Gest PE, Zerilli A, Le Flohic AM. The extent of oral fungal flora in 353 students and possible relationships with dental caries. Caries Res. 2001;35:149-55.

34. Muzurovic S, Babajic E, Masic T, Smajic R, Selmanagic A. The relationship between oral hygiene and oral colonisation with Candida species. Med Arh. 2012;66:415-7.

35. Roskiewicz D, Daniluk T, Zaremba ML, Cylwik-Rokicka D, Stokowska W, Pawinska M, Dabrowska E, Marcuk-Kolada G, Waszkiel D. Oral Candida albicans carriage in healthy preschool and school children. Adv Med Sci. 2006;51 Suppl 1:187-90.

36. Russell Jl, Mac Farlane TW, Aitchison TC, Stephen KW, Burchell CK. Salivary levels of mutans streptococci, Lactobacillus, Candida, and Veilonella species in a group of Scottish Adolescents. Community Dent Oral Epidemiol. 1990;18:17-21.

37. Arendorf T, Addy M. Candida carriage and plaque distribution before, during and after removable orthodontic appliance therapy. J Clin Periodontol. 1985;12:360-8.

38. Hildebrandt $\mathrm{GH}$, Bretz WA. Comparison of culture media and chairside assays for enumerating mutans streptococci. J Appl Mlcrobiol. 2006;100:1339-47.
39. Samaranayake LP, Mac Farlane TW, Lamey PJ, Ferguson MM. A comparison of oral rinse and imprint sampling techniques for the detection of yeast, coliform and Staphylococcus aureus carriage in the oral cavity. J Oral Pathol. 1986;15:386-8.

40. Aas JA, Griffen AL, Dardis SR, Lee AM, Olsen I, Dewhirst FE, Leys EJ, Paster BJ. Bacteria of dental caries in primary and permanent teeth in children and young adults. J Clin Microbiol. 2008:46:1407-17.

41. Badet C, Thebaud N. Ecology of lactobacilli in the oral cavity: a review of literature. Open Microbiol J. 2008;2:38-48.

42. Sansone C, Van Houte J, Joshipura K, Kent R, Margolis HC. The Association of mutans streptococci and non-mutans streptococci capable of acidogenesis at a low pH with dental caries on enamel and root surfaces. J Dent Res. 1993; 72:508-16

43. Arneberg P, Ögaard B, Scheie AA, Rölla G. Selection of streptococcus mutans and lactobacilli in an intra-oral human caries model. J Dent Res. 1984:63:1197-200.

44. Raja M, Hannan A, Ali K. Association of oral candida carriage with denta caries in children. Caries Res. 2010:44:272-6.

45. Yang XQ, Zang Q, Lu LY, Yang R, Liu Y, Zou J. Genotypic distribution of Candida albicans in dental biofilm of Chinese children associated with severe early childhood caries. Arch Oral Biol. 2012;57:1048-53.

46. Srivastava B, Bhatia HP, Chaudhary V, Aggarwal A, Kumar Singh A, Gupta N. Comparative evaluation of oral Candida albicans carriage in children with and without dental caries: a microbiological in vivo study. Int J Clin Pediatr Dent. 2012;5:108-12.

47. Lied TR, Kazandjian VA. A Hawthorne strategy: implications for performance measurement and improvement. Clin Perform Qual Health Care. 1998;6:201-4.

\section{Submit your next manuscript to BioMed Central and we will help you at every step:}

- We accept pre-submission inquiries

- Our selector tool helps you to find the most relevant journal

- We provide round the clock customer support

- Convenient online submission

- Thorough peer review

- Inclusion in PubMed and all major indexing services

- Maximum visibility for your research

Submit your manuscript at www.biomedcentral.com/submit
) Biomed Central 